\title{
Understanding and overcoming major barriers in
} cancer nanomedicine

\author{
"Nanoparticles ... open up new possibilities in integrated cancer imaging and \\ therapy. However, at present there are several fundamental problems and technical \\ barriers that must be understood and overcome."
}

Cancer nanomedicine is currently under intense development for applications in cancer imaging, molecular diagnosis and targeted therapy [1-6]. The basic rationale is that nanometer-sized particles, such as quantum dots (QDs), colloidal gold and polymeric nanomicelles, have functional and structural properties that are not available from either discrete molecules or bulk materials [7-10]. When conjugated with targeting ligands such as monoclonal antibodies, peptides or small molecules, these nanoparticles can be used to target malignant tumor cells and the tumor microenvironment (e.g., tumor stroma and tumor vasculatures) with high specificity and affinity. In the 'mesoscopic' size range of 10 to $100 \mathrm{~nm}$, nanoparticles also have large surface areas for conjugating to multiple diagnostic and therapeutic agents, opening up new possibilities in integrated cancer imaging and therapy.

\section{"...the use of tumor-targeting ligands does not influence the total nanoparticle accumulation in a solid tumor, but does function to increase receptor-mediated internalization..."}

However, at present there are several fundamental problems and technical barriers that must be understood and overcome. These problems include nanoparticle surface opsonization (surface 'fouling' by nonspecific protein adsorption) [11-13], nanoparticle uptake and retention in reticuloendothelial organs (e.g., liver and spleen $[14,15]$, difficulties in nanoparticle targeting and penetration in solid tumors [16,17], and the long-term fate and toxicity concerns of nanoparticles, especially nonbiodegradable nanomaterials containing toxic elements [18-20]. Thus, there is an urgent need to study these problems and to develop innovative strategies for overcoming them. In this article, we briefly discuss the major challenges and opportunities in developing cancer nanomedicine for molecular imaging, in vitro diagnostics and targeted therapy.

\section{Opsonization \& phagocytosis}

Opsonization is the process by which a foreign organism or particle becomes covered with nonspecific proteins, thereby making it more visible to phagocytic cells (e.g., monocytes, macrophages, neutrophils and dendritic cells). After opsonization, phagocytosis can occur, which is the engulfing and eventual destruction or removal of foreign materials such as nanoparticles from the bloodstream. Depending on their surface properties, such as charge and hydrophobicity, nanometer-sized particles have been shown to be 'opsonized' (coated by opsonin proteins) within minutes upon exposure to blood (Figure 1). It is thought that the nature of this protein adsorption will ultimately determine the fate of the nanoparticles, causing removal from circulation by the mononuclear phagocyte system and polymorphonuclear phagocytes [21]. Recent work by Cedervalli indicates that the initial adsorption of proteins results in a corona that will determine further interactions with other proteins and cells [22]. In general, the primary forces for protein adsorption on nanoparticles are hydrophobic and electrostatic interactions, together with conformational changes and associated changes in entropy [23-25]. The blood plasma proteins involved in 'fouling' nanoparticles are mainly albumins, fibronectins, complement proteins, fibrinogens, immunoglobulins and apolipoproteins [26-29].

After opsonization, the next step is the attachment of phagocytes to nanoparticles via surface-bound proteins. Without the presence of surface-bound or adsorbed opsonin proteins, the phagocytes are typically not able to bind or recognize the foreign particles. One method of attachment occurs when the bound opsonin

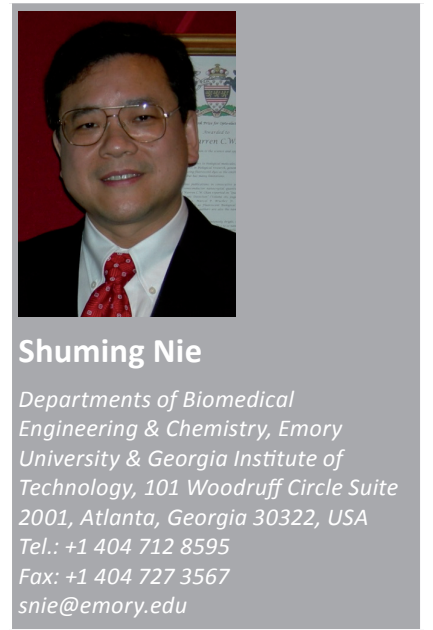

future medicine $^{\text {pind }} \mathbf{f S g}$ 


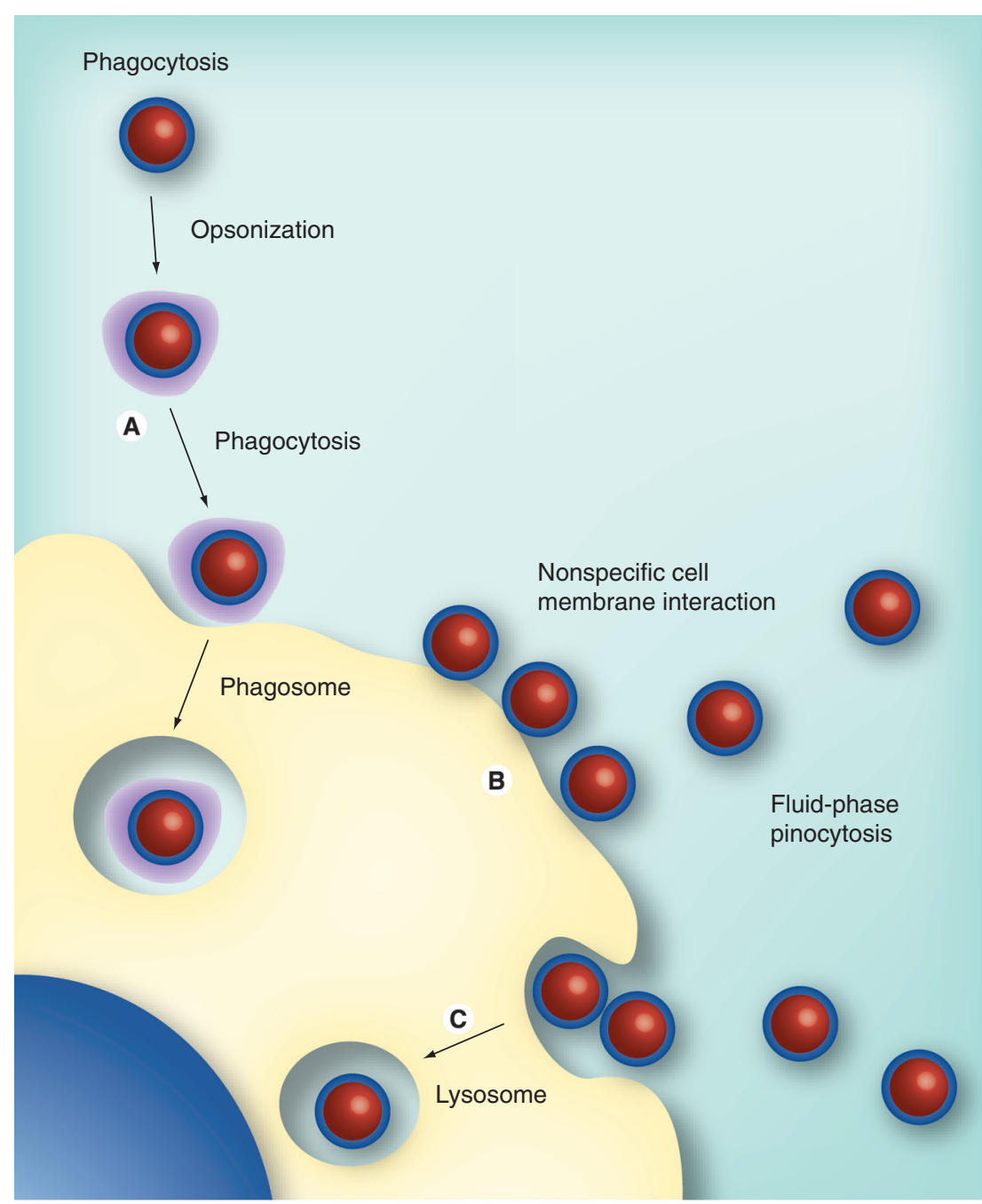

Figure 1. Nanoparticle interactions with plasma proteins and blood immune cells. The main modes of interactions include $(\mathbf{A})$ nonspecific protein adsorption on the particle surface (opsonization) and phagocytosis by leukocytes (e.g., monocytes), (B) nonspecific nanoparticle-cell membrane interactions (electrostatic or hydrophobic) and (C) fluid-phase pinocytosis. Adapted with permission from Aaron Mohs, Nie Group, Emory University, GA, USA. proteins undergo conformational changes from an inactive protein present in the blood serum to an activated protein structure that can be recognized by phagocytes. Phagocytic cell surfaces contain specialized receptors that interact with the modified conformation of these various opsonins, thus alerting them to the presence of a nanoparticle. A second type of attachment is the nonspecific adherence of phagocytes to surface adsorbed serum proteins, which stimulates phagocytosis [30]. The final result is the binding and phagocytosis of nanoparticles by the mononuclear phagocytes.

Neutrally charged particles have a much lower opsonization rate than charged particles [31]. One method to reduce opsonization is the use of surface adsorbed or grafted shielding groups to block the electrostatic and hydrophobic interactions. Important examples include polysaccharides (dextrans) and polyethylene glycols (PEGs). These polymers are very flexible and highly hydrophilic, which can help 'shield' hydrophobic or charged particles from blood proteins. Recent work by Smith, Nie and coworkers [32-34] has shown that the hydrodynamic size (not the dry size) is a key factor in determining how nanoparticles interact with blood proteins and cell membranes. Nonspecific protein adsorption and cell membrane binding can be reduced to very low levels when the hydrodynamic sizes of nanoparticles such as QDs are reduced to 4-8 $\mathrm{nm}$ in diameter. The rationale is that when the nanoparticles have similar sizes as serum proteins, their collision kinetics and contact areas are minimized - that is, neither the particle nor the protein has enough contact points for the other to grab or 'land'. This is an important insight that we will use to develop small and 'nonsticky' QDs that are resistant to nonspecific protein adsorption and opsonization.

\section{Reticuloendothelial system organ uptake \& retention}

The reticuloendothelial system (RES) is part of the immune system and consists of the phagocytic cells such as monocytes and macrophages. Macrophages located in the liver (termed Kupffer cells) and the spleen rapidly take up opsonized nanoparticles (coated with serum proteins). Nanoparticles are usually taken up by the liver, spleen and other parts of the RES, depending on their size and surface characteristics. Particles with more hydrophobic surfaces are preferentially taken up by the liver, followed by the spleen and lungs [35]. Hydrophilic nanoparticles (below $35 \mathrm{~nm}$ diameter) show much less uptake by the spleen and liver. Surface modification by PEG reduces the opsonization and minimizes the clearance by the RES, leading to longer blood circulation times and improved pharmacokinetic properties. At present, the most promising strategies in reducing RES uptake are to reduce the particle size and to sterically stabilize the nanoparticles with a layer of amphiphilic polymer chains such as PEG. Most recently, Li and Huang reported a PEGylated lipid nanoparticle with nearly complete charge shielding for siRNA delivery into solid tumors [36]. This particle is believed to 'evade' the RES system, and is able to deliver $32.5 \%$ of the injected dose into tumors in a xenograft model. However, a complete avoidance of the RES system has not 
been possible, and the shielded or 'camouflaged' nanoparticles can evade the phagocytes, but cannot avoid eventual uptake.

\section{Active versus passive targeting}

Nanoparticles can be delivered to tumors by both active and passive targeting mechanisms (Figure 2). In the passive mode, nanometer-sized particles are accumulated preferentially at tumor sites through an enhanced permeability and retention effect [37-39]. For active tumor targeting, ligand molecules such as antibodies and peptides are often used to recognize specific tumor antigens. It is well known that tumors tend to have leaky vasculature and a poorly functional lymph system [37-39]. Nanoparticles with sizes of $10-100 \mathrm{~nm}$ are often not cleared by renal filtration (renal clearance) and accumulate at the tumors after prolonged circulation. The level of nanoparticle tumor accumulation depends on

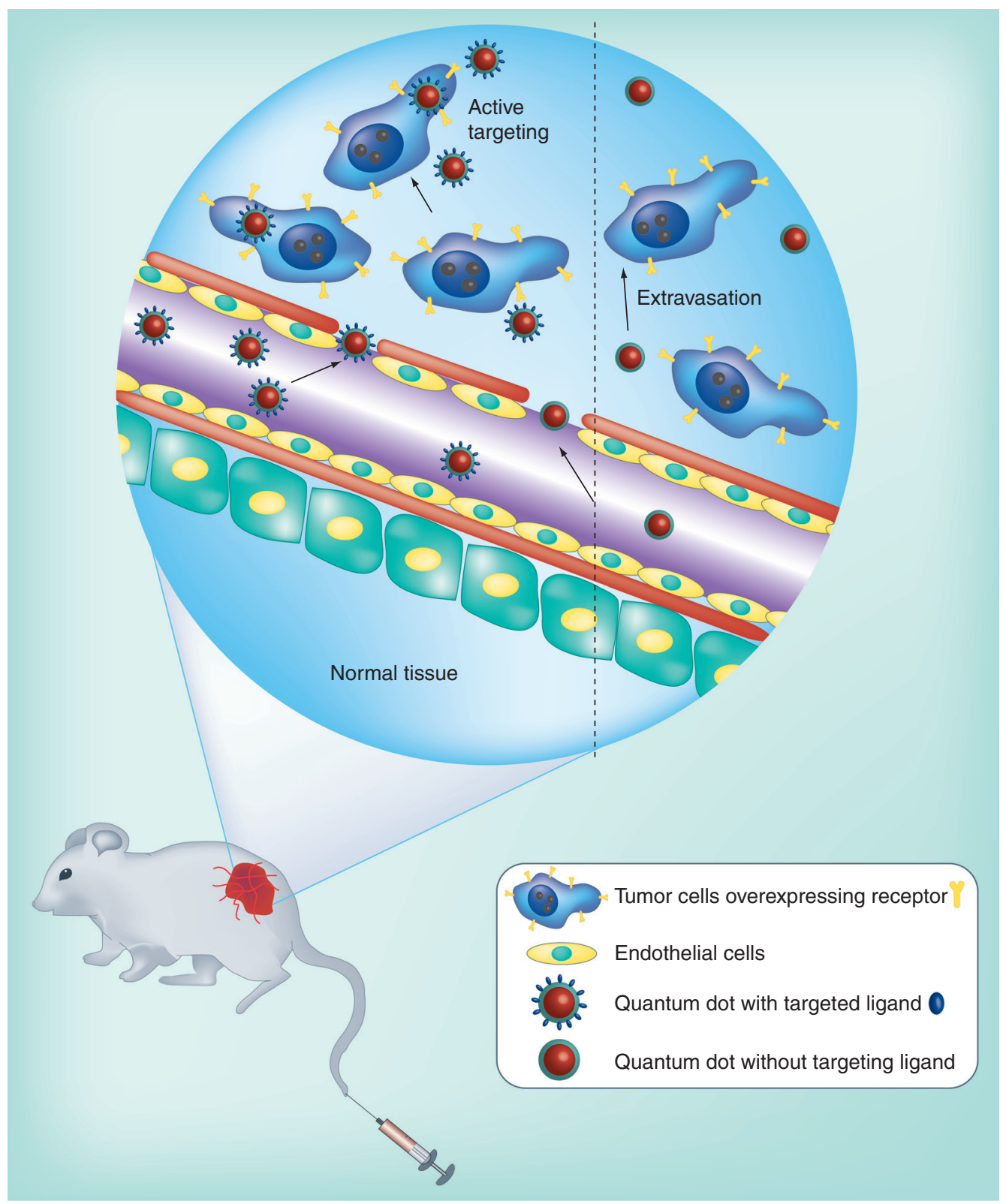

Figure 2. Quantum dots involved in both active and passive tumor targeting. In the passive mode, nanometer-sized particles such as quantum dots accumulate at tumor sites through an enhanced permeability and retention effect. For active tumor targeting, nanoparticles are conjugated to molecular ligands such as antibodies and peptides to recognize protein targets that are overexpressed on the surface of tumor cells such as the EGF receptor, the transferrin receptor or the folate receptor.

Adapted with permission from Ximei Qian, Nie Group, Emory University, GA, USA. 
various factors such as the nanoparticle size, the leaky vascular pore, the blood circulation half-life (longer half-lives lead to higher accumulation), the degree of tumor vascularization (less accumulation in poorly vascularized tumors) and the degree of angiogenesis (poor accumulation in small preangiogenic or large necrotic tumors).

At present, there is still considerable debate about the relative contributions of active versus passive targeting in nanoparticle delivery [40]. Several recent papers indicate that the use of tumor-targeting ligands does not influence the total nanoparticle accumulation in a solid tumor, but does function to increase receptor-mediated internalization and could improve therapeutic efficacy for cancer drugs that affect intracellular protein targets $[41,42]$. On the other hand, there are experimental data suggesting that active ligand targeting increases both intracellular nanoparticle uptake and total tumor accumulation [43-48]. This apparent discrepancy is most likely caused by differences in the nanoparticle coatings, in the type of tumor models, and in the type of targeting ligands (e.g., small molecules, peptides or whole antibodies).

\section{Future perspective}

Looking into the future, there are a number of research directions that are particularly promising but require concerted effort for success. These include:

- Design and development of multifunctional nanoparticles for integrated cancer imaging and therapy (theranostic nanoparticles) [49];

- Use of multiplexed nanoparticles in in vitro or ex vitro diagnostics (such as tissue specimens and circulating tumor cells) to study cancer behavior, clinical outcome, treatment response and individualized therapy [3];
- Design and development of biocompatible nanoparticles to overcome nonspecific organ uptake and RES scavenging;

- Penetration of imaging and therapeutic nanoparticles into solid tumors beyond the first few layers of vascular endothelial cells. This task will likely require active pumping mechanisms, such as caveollin transcytosis and receptor-mediated endocytosis, or cell-based strategies, such as nanoparticle-loaded macrophages [50,51];

- Release of drug payloads inside targeted cells or organs. This task will likely require the development of biodegradable nanoparticle carriers that are responsive to $\mathrm{pH}$, temperature or enzymatic reactions;

- Nanotoxicology studies including nanoparticle distribution, excretion, metabolism, and pharmacokinetics and pharmacodynamics in in vivo animal models;

- Standardization and manufacturability. For future use in human patients, the nanoparticles must be standardized and must be manufactured in compliance with US FDA requirements.

\section{Financial \& competing interests disclosure}

This work was supported by grants from the NCI Centers of Cancer Nanotechnology Excellence (CCNE) Program (U54CA119338) and the Bioengineering Research Partnerships Program (BRP) (R01CA108468). Shuming Nie is a Distinguished Cancer Scholar of the Georgia Cancer Coalition (GCC). The author has no other relevant affiliations or financial involvement with any organization or entity with a financial interest in or financial conflict with the subject matter or materials discussed in the manuscript apart from those disclosed.

No writing assistance was utilized in the production of this manuscript.

\section{Bibliography}

Papers of special note have been highlighted as: - of interest

" " of considerable interest

1 Ferrari M: Cancer nanotechnology: opportunities and challenges. Nat. Rev. Cancer 5, 161-171 (2005).

- Excellent review article describing the promises and challenges in cancer nanotechnology and nanomedicine.

2 Riehemann K, Schneider SW, Luger TA et al: Nanomedicine - challenge and perspectives. Angew. Chem. Intl. Ed. 48, 872-897 (2009).
3 Nie SM, Xing Y, Kim GJ et al.: Nanotechnology applications in cancer. Ann. Rev. Biomed. Eng. 9, 257-288 (2007).

- Comprehensive review article summarizing nanotechnology applications in cancer imaging, diagnostics and targeted therapy.

4 Sanhai WR, Sakamoto JH, Canady R et al: Seven challenges for nanomedicine. Nat. Nanotechol. 3, 242-244 (2008).

5 Heath JR, Davis ME: Nanotechnology and cancer. Ann. Rev. Med. 59, 251-265 (2008).

6 Farokhzad OC, Langer R: Nanomedicine: developing smarter therapeutic and diagnostic modalities. Adv. Drug Deliv. Rev. 58, 1456-1459 (2006).

7 Alivisatos P: The use of nanocrystals in biological detection. Nat. Biotechnol. 22, 47-52 (2004).

8 Gao XH, Yang L, Petros JA et al.: In vivo molecular and cellular imaging with quantum dots. Curr. Opin. Biotechnol. 16, 63-72 (2005).

9 Liu Z, Cai W, He L et al.: In vivo biodistribution and highly efficient tumor targeting of carbon nanotubes in mice. Nat. Nanotechnol. 2, 47-52 (2007). 
10 Gao X, Cui Y, Levenson RM, Chung LWK, Nie SM: In vivo cancer targeting and imaging with semiconductor quantum dots. Nat. Biotechnol. 22, 969-976 (2004).

-1- First report of using bioconjugated quantum dots (QDs) for in vivo tumor targeting and imaging in live animal models.

11 Owens DE, Peppas NA: Opsonization, biodistribution, and pharmacokinetics of polymeric nanoparticles. Int. J. Pharm. 307, 93-102 (2006).

12 Moghimi SM, Hunter AC, Murray JC: Nanomedicine: current status and future prospects. FASEB J. 19, 311-330 (2005).

13 Moghimi SM, Hunter AC, Murray JC: Long-circulating and target-specific nanoparticles: theory to practice. Pharmacol. Rev. 53, 283-318 (2001).

14 Jain RK: Delivery of molecular medicine to solid tumors: lessons from in vivo imaging of gene expression and function. J. Control. Release 74, 7-25 (2001).

15 Jain RK: Physiological barriers to delivery of monoclonal antibodies and other macromolecules in tumors. Cancer Res. 50, 814-819 (1990).

16 Minchinton Al, Tannock IF: Drug penetration in solid tumours. Nature Rev. Cancer 6, 583-592 (2006).

17 Dreher MR, Liu WG, Michelich CR et al: Tumor vascular permeability, accumulation, and penetration of macromolecular drug carriers. J. Natl Cancer Inst. 98, 335-344 (2006).

- Reports quantitative tumor penetration data for macromolecules and nanoparticles by using fluorescently labeled dextran as an imaging tracer.

18 Nel AE, Madler L, Velegol D et al.: Understanding biophysicochemical interactions at the nano-bio interface. $N a t$. Mater. 8, 543-557 (2009).

19 Dobrovolskaia MA, McNeil SE: Immunological properties of engineered nanomaterials. Nat. Nanotechnol. 2(8), 469-478 (2007).

20 Stern ST, McNeil SE: Nanotechnology safety concerns revisited. Toxicol. Sci. 101, 4-21 (2008).

21 Moghimi S, Szebeni J: Stealth liposomes and long circulating nanoparticles: critical issues in pharmacokinetics, opsonization and protein-binding properties. Prog. Lipid Res. 42, 463-478 (2003).

22 Cedervall T, Lynch I, Lindman S et al.: Understanding the nanoparticle-protein corona using methods to quantify exchange rates and affinities of proteins for nanoparticles. Proc. Natl Acad. Sci. USA 104, 2050-2055 (2007).
23 Gessner A, Lieske A, Paulke B, Müller R: Influence of surface charge density on protein adsorption on polymeric nanoparticles: analysis by two-dimensional electrophoresis. Eur. J. Pharm. Biopharm. 54, 165-170 (2002).

24 Vonarbourg A, Passirani C, Saulnier P, Benoit J: Parameters influencing the stealthiness of colloidal drug delivery systems. Biomaterials 27, 4356-4373 (2006).

25 Lück M, Paulke B, Schröder W, Blunk T, Müller R: Analysis of plasma protein adsorption on polymeric nanoparticles with different surface characteristics. J. Biomed. Mater. Res. 39, 478-485 (1998).

26 Gref R, Lück M, Quellec P et al.: 'Stealth' corona-core nanoparticles surface modified by polyethylene glycol (PEG): influences of the corona (PEG chain length and surface density) and of the core composition on phagocytic uptake and plasma protein adsorption. Colloids Surf. B Biointerfaces 18 , 301-313 (2000).

27 Moore A, Weissleder R, Bogdanov A Jr: Uptake of dextran-coated monocrystalline iron oxides in tumor cells and macrophages. J. Magn. Reson. Imaging 7, 1140-1145 (1997).

28 Cedervall T, Lynch I, Foy M et al.: Detailed identification of plasma proteins adsorbed on copolymer nanoparticles. Angew Chem. Int. Ed. Engl. 46, 5754-5756 (2007).

29 Lundqvist M: Nanoparticle size and surface properties determine the protein corona with possible implications for biological impacts. Proc. Natl Acad. Sci. USA 105, 14265-14270 (2008).

30 Frank M, Fries L: The role of complement in inflammation and phagocytosis. Immunol. Today 12, 322-326 (1991).

31 Roser M, Fischer D, Kissel T: Surfacemodified biodegradable albumin nano- and microspheres. II. Effect of surface charges on in vitro phagocytosis and biodistribution in rats. Eur. J. Pharm. Biopharm. 46, 255-263 (1998).

32 Smith AM, Duan HW, Mohs AM, Nie SM: Bioconjugated quantum dots for in vivo molecular and cellular imaging. $A d v$. Drug Deliv. Rev. 60, 1126-1140 (2008).

33 Smith AM, Nie SM: Minimizing the hydrodynamic size of quantum dots with multifunctional multidentate polymer ligands. J. Am. Chem. Soc. 130, 11278-11279 (2008).

- Reports a new generation of size-minimized QDs based on the use of multidentate polymer coating materials.

34 Smith AM, Nie SM: Next-generation quantum dots. Nat. Biotechnol. 26, 732-733 (2009).
35 Brannon-Peppas L, Blanchette JO: Nanoparticle and targeted systems for cancer therapy. Adv. Drug Deliv. Rev. 56, 1649-1659 (2004).

36 Li SD, Huang L: Nanoparticles evading the reticuloendothelial system: role of the supported bilayer. Biochim. Biphys. Acta. 1788(10), 2259-2266 (2009).

37 Jain RK: Transport of molecules, particles, and cells in solid tumors. Ann. Rev. Biomed. Eng. 1, 241-263 (1999).

38 Maeda H, Wu J, Sawa T et al.: Tumor vascular permeability and the EPR effect in macromolecular therapeutics: a review. J. Control. Release 65, 271-284 (2000).

39 Matsumura $\mathrm{Y}$, Maeda $\mathrm{H}$ : A new concept for macromolecular therapeutics in cancerchemotherapy - mechanism of tumoritropic accumulation of proteins and the antitumor agent smancs. Cancer Res. 46, 6387-6392 (1986).

- Classic work reporting tumor enhanced permeability and retention (EPR) and its effect on drug delivery.

40 Pirollo KF, Chang EH: Does a targeting ligand influence nanoparticle tumor localization or uptake? Trends Biotechnol. 26, 552-555 (2008).

41 Bartlett DW, Su H, Hildebrandt IJ, Weber WA, Davis ME: Impact of tumorspecific targeting on the biodistribution and efficacy of siRNA nanoparticles measured by multimodality in vivo imaging. Proc. Natl Acad. Sci. USA 104, 15549-15554 (2007).

=- Outstanding work showing that active molecular targeting does not increase the total accumulation of nanoparticles in solid tumors.

42 Kirpotin DB, Drummond DC, Shao Y et al.: Antibody targeting of long-circulating lipidic nanoparticles does not increase tumor localization but does increase internalization in animal models. Cancer Res. 66, 6732-6740 (2006).

" Reports convincing data indicating that active molecular targeting does not increase the total accumulation of liposomes in solid tumors, but can lead to improved cellular internalization via receptor-mediated endocytosis and better drug efficacy.

43 Garanger E, Boturyn D, Dumy P: Tumor targeting with RGD peptide ligands-design of new molecular conjugates for imaging and therapy of cancers. Anticancer Agents Med. Chem. 7, 552-558 (2007).

44 de Bruin K, Ruthardt N, von Gersdorff K et al:: Cellular dynamics of EGF receptortargeted synthetic viruses. Mol. Ther. 15, 1297-1305 (2007). 
45 Hilgenbrink AR, Low PS: Folate receptormediated drug targeting: from therapeutics to diagnostics. J. Pharm. Sci. 94, 2135-2146 (2005).

46 Xu L, Pirollo KF, Tang WH, Rait A, Chang EH: Transferrin-liposome-mediated systemic 53 gene therapy in combination with radiation results in regression of human head and neck cancer xenografts. Hum. Gene Ther. 10, 2941-2952 (1999).

47 Daniels TR, Delgado T, Rodriguez JA, Helguera G, Penichet ML: The transferrin receptor part I: biology and targeting with cytotoxic antibodies for the treatment of cancer. Clin. Immunol. 121, 144-158 (2006).

48 Dass CR, Choong PF: Selective gene delivery for cancer therapy using cationic liposomes: in vivo proof of applicability. J. Control Release 113, 155-163 (2006).

49 Sumer B, Gao JM: Theranostic nanomedicine for cancer. Nanomedicine 3, 137-140 (2008).

50 Oh P, Borgstrom P, Witkiewicz H et al.: Live dynamic imaging of caveolae pumping targeted antibody rapidly and specifically across endothelium in the lung. Nat. Biotechnol. 25, 327-337 (2007).
" - Detailed studies showing that caveolae pumping can be exploited for active transport of antibodies across the vasculature endothelium.

51 Sugahara KN, Teesalu T, Karmali PP et al: : Tissue-penetrating delivery of compounds and nanoparticles into tumors. Cancer Cell $16,510-520$ (2009).

- A potential breakthrough showing that a class of peptides could be used to deliver imaging and therapeutic nanoparticle agents into solid tumors. 